Arturo Tienken L.

\title{
Bernard Shaw, reformador
}

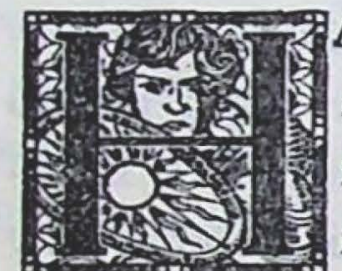

AN transcurrido cien años desde que nació George Bernard Shaw - "G. B. S."- y seis desde su muerte. El recuerdo de su personalidad y de su obra perdura en nuestro tiempo con suma claridad. Durante más de sesenta años, durante dos generaciones enteras, se escuchó su airada voz a veces con desprecio, a veces con respeto, pero jamás con indiferencia. $\mathrm{Y}$ a su muerte, economistas, políticos, hombres de ciencia y toda la vasta familia literaria le tributaron sentidos homenajes. En un emocionado artículo (revista The New Statesman and Nation, 18 de noviembre de 1951), el filósofo C. E. M. Joad escribe: "La primera vez que vi a Shaw fué en 1913 en los Examination Schools, Oxford, donde vino a dictar unas conferencias sobre los orígenes del drama. Shaw se encontraba en el apogeo de la primera fase de su gloria, y el recinto rebosaba de profesores y estudiantes reunidos allí para rendirle culto. Cuando, con paso firme, el gran hombre entró por el pasillo, el rojo pelo de su barba erizado de vitalidad, los colegios se estremecieron con aplausos; y yo, encaramado en lo alto de un ventanal, me sentí embargado por el más puro sentimiento de adoración que jamás haya sentido por ser humano".

Para nosotros, los más jóvenes, Bernard Shaw es, ante todo, un gran dramaturgo; pero para su generación fué mucho más que eso: fué una influencia viviente, una mentalidad preclara cuyos destellos 
irrumpieron en las tinieblas de la ignorancia e iluminaron el camino de la justicia y de la verdad. Fué el gran derribador de poses, el destructor de prejuicios sociales en una era repleta de poses y prejuicios. Shaw compartió con Wells el honor de destruir gran parte de la complacencia victoriana, "de abrir las cortinas para dejar entrar la luz”, según Joad. Y al igual que Wells, llegó a la cumbre de la fama mediante su talento y su personalidad, sin influencias y sin dinero.

De su padre, George Carr Shaw, heredó un irrefrenable sentido del humor, y de su madre, Elizabeth Gurly, una educación musical que a la postre le proporcionó en Londres medios para ganarse la vida en calidad de crítico musical. A su decir, en el colegio no aprendió absolutamente nada, abandonando las aulas a los quince años. "El colegio es un lugar donde ponen a Julio César y Horacio en manos de párvulos con la esperanza de que el resultado les signifique un conocimiento del mundo. Yo me refugié en la inactividad y en la holgazanería más completa, adquiriendo en casa y sin saberlo un conocimiento que me permitió lidiar en la vida en igualdad de condiciones con hombres que sólo entienden de gramática clásica y pronuncian mal a los poetas y filósofos griegos y latinos".

Entre los quince y los veinte años trabajó en una oficina de corretajes, demostrando grandes aptitudes como cajero; pero su temperamento inquieto se rebeló contra una existencia tan organizada y apacible, y de la noche a la mañana, se trasladó a Londres, donde su madre residía desde algún tiempo. Vivió a sus expensas durante aquellos años de formación intelectual escribiendo cinco extensas novelas que fueron rechazadas por las casas editoras. Shaw cuenta, con su infaltable buen humor, que las guardó dentro de un cajón.

Ahí las encontraron los ratones y se las comieron en parte; pero ni los ratones fueron capaces de terminarlas. En nueve años de trabajo con su pluma ganó apenas la cantidad de seis libras esterlinas. Estos años de juventud en Londres formaron su recia personalidad. Frecuentó las galerías de arte y los conciertos, el Museo Británico (donde, según Shàw, recibió su educación), asistió a innumerables conferencias, leyó a Karl Marx, formó parte de avanzadas agrupacio- 
nes políticas, habló en mítines callejeros apoyando al socialismo, a la abstinencia y el sistema vegetariano. Como resultado aprendió a expresarse, adquirió experiencia, vastos conocimientos sobre las más diversas materias y convicciones. Posteriormente, ingresó al periodismo en calidad de crítico de arte, tanto como literario, teatral y musical, y desde su nueva tribuna empezó a formarse un público. El escritor Hesketh Pearson en su biografía del célebre dramaturgo (Bernard Shaw, Collins, London, 1950), captó magistralmente el sabor de aquella época, época plena de acontecimientos serios y humorísticos en la vida de Shaw, y a la cual pertenece su amistad con Sidney Webb y la famosa agrupación socialista "the Fabian Society".

Fué en la biblioteca del Museo Británico donde Shaw conoció al crítico William Archer, que se haría famoso-con sus traducciones de las obras de Ibsen. A Archer le llamó la atención un personaje que a menudo se sentaba cerca de él, cuya apariencia era tan extraña como sus gustos: un hombre de cutis pálido y de barba de un rojo vivo que estudiaba la partitura orquestal de Tristán e Isolda entre capítulos de Das Kapital. Archer le ofreció, después de algunos divertidos preámbulos, la oportunidad de escribir crítica literaria, y aunque no demostró en estos temas el mismo talento que en la crítica teatral y musical, expresó muchos conceptos interesantes. Uno de sus escritos empieza así: "Durante el mes pasado se infligió al arte un golpe extraordinariamente rudo por parte del Royal Academy, al iniciar su exposición anual en Burlington House". En otra ocasión afirmó: "Si no se escribe de una manera irritante, es mejor no escribir, ya que la gente no se molesta por cosas que, a su vez, no la molestan".

Al poco tiempo empezó a escribir crítica musical y de teatro, como ya se ha dicho. Lució aptitudes especiales que le valieron el temor y el respeto de artistas y del público. Hoy en día sus juicios musicales demuestran una exactitud y penetración que los hacen todavía valederos. Su libro $E l$ perfecto wagneriano es un estudio de las opiniones revolucionarias del gran músico alemán a través del ciclo de los Nibelungos; es decir, una interpretación shawiana de la ópera de Wagner, sobre la base de las ideas políticas de este músico. Cuando 
el teatro renovador de Ibsen hizo su aparición, Shaw lo defendió con energía y publicó un libro, La quintaesencia del ibsenismo, una tesis personal en que interpreta a Ibsen desde su propia actitud antirromántica. Shaw se interesó por toda clase de problemas sociales, y en ellos hizo imperar un criterio realista. En uno de sus prefacios cuenta cómo un oculista le dijo que su visión era completamente normal, hecho infrecuente del cual gozaba sólo el diez por ciento de la población. Shaw mantuvo que su visual mental gozaba de igual normalidad y estaba exenta de las torcidas ilusiones románticas que rigen a la sociedad cuando ésta se autoexamina. Shaw pensaba que el sentimentalismo era una de las herejías que debían excluirse del arte y de la vida y procuró implantar como norma la honradez intelectual entre sus semejantes. La constante cruzada de su vida consistió en hacer pensar a la humanidad, en imponer la conciencia por sobre la costumbre. Sus obras son aplicaciones prácticas a varios aspectos de nuestra civilización de su bien humorada pero mortífera lógica intelectual. El teatro de Shaw es un teatro de tesis, un instrumento mediante el cual Shaw destruye concepciones comunes que la sociedad acepta como verídicas. Shaw nos confronta con la inesperada realidad que yace detrás de una creencia común, forzando de esta manera una comparación y una crítica. La guerra, el amor, la propiedad, la pobreza, el matrimonio, la prostitución, el problema de Irlanda, la educación, la religión y la ciencia como también los políticos, la profesión médica y algunos personajes históricos, dieron tema a nuestro dramaturgo para exponer sus innumerables teorías.

Durante aquella época en que Shaw se ganaba la vida como periodista a la vez que dedicaba su privilegiado intelecto a los problemas que más tarde formarían la base de su teatro, el drama literario de Inglaterra no producía ninguna obra de importancia. En efecto, desde 1777, año que vió el estreno de la famosa comedia de Sheridan The School for Scandal, hasta 1892 -había transcurrido más de un siglo- no aparece en el teatro inglés ninguna obra notable. Shaw le infundió nueva vida con Widowers House. Se dan varias razones para justificar este enorme vacío, que, desde luego, no se debe a falta de 
talento, pues Inglaterra contó en aquella centuria con escritores célebres en todos los otros géneros literarios. Creadores genuinos cuyos nombres son por demás conocidos enriquecieron la historia cultural de aquella nación. Cabe mencionar que Browning, Tennyson y Swinburne, entre otros, escribieron obras poéticas en forma de drama, pero apenas adecuadas para ser puestas en escena por no reunir los elementos esenciales de buen teatro. Según los apologistas, la clase adinerada se empeñaba en aumentar sus riquezas y en consolidar el Imperio. Las clases trabajadoras sumidas en la pobreza, carecían de la cultura necesaria para poder apreciar un espectáculo de mayor jerarquía. Debido a la influencia puritana que aún prevalecía en grandes sectores de la población, había mucha gente que anatematizaba contra el teatro, creyéndolo un espectáculo inmoral, y los públicos no eran en consecuencia muy selectos.

El burgués "respetable" no asistía por razones doctrinarias y en verdad los desmanes que solían producirse en los teatros más pequeños justificaban esta ausencia. En suma, el ambiente no era propicio y aún más, el escritor de talento contaba con mayores posibilidades de ganar fortuna en el género novelístico.

Sin embargo, había teatro; pero un teatro formalista y sencillo con situaciones, personajes y sentimientos estereotipados, en que después de tres actos de hechos y coincidencias a menudo absurdas, el villano recibía su castigo y el amor verdadero se imponía triunfante. El mismo sentimentalismo y el argumento mecanizado que impera hoy en día en las producciones cinematográficas de segundo orden, eran también el pábulo de aquel público.

A mediados del siglo diecinueve Francia era posiblemente la nación que ofrecía el mejor teatro de Europa. Scribe y Sardou escribieron obras de sólida estructura pero carentes de valor espiritual. Posteriormente Alejandro Dumas, hijo, y Emile Augier añadieron este factor con sus obras de tesis, entre las cuales se destaca La Dame aux Camelias, famosa en su tiempo, que hizo escuela en Inglaterra con Sir Arthur Pinero. La obra de Pinero The Second Mrs. Tanqueray, marca una etapa en el teatro inglés. Fué puesta en escena el mismo 
año que Widowers Houses de Bernard Shaw. Junto con estos nombres figura el de Henry Arthur Jones, quien insistió en que el drama debe ser una crítica incondicional de las costumbres e instituciones de un pueblo. Pero ni Pinero ni Jones eran pensadores originales o profundos, ni se atrevieron a examinar la estructura social de la época con la penetración de Henrik Ibsen en Noruega y su más entusiasta discípulo inglés, Bernard Shaw.

Ibsen puso a las tablas en contacto con la vida y desde ellas atac $\delta$ el convencionalismo y aquellas costumbres que a su entender impedían el libre desenvolvimiento del individuo en su medio ambiente. Ibsen estimuló a Shaw de tal manera que, después de La quintaesencia del ibsenismo (1891), éste se dedicó a escribir teatro según los cánones ibsenianos. No debe suponerse que Shaw sea un mero imitador del noruego; pero de él aprendió que una pieza teatral debe abordar algún tema de interés general. En la epístola dedicatoria de Man and Superman Shaw, refiriéndose a la frase tan corriente en aquellos días "Art for Art's Sake" - el arte por el arte- dice: "Yo no me molesto en escribir una sola frase por el arte”. El drama, según Ibsen -y por ende según Shaw- debe reflejar los problemas que acosan a la sociedad, en lugar de escapar a los mundos imaginarios del romanticismo; aún más, tiene la obligación de convertirse en un severo pontífice de su tiempo. Los públicos vieron obras plenas de franqueza desacostumbrada que puso en descubierto heridas sociales en plena descomposición. Espectros tiene como base el efecto de las enfermedades venéreas. Para los pundonorosos victorianos, acostumbrados a las bellezas tenysonianas, tales temas parecieron execrables e indignos de mención. Ibsen ha sido motivo de apreciaciones diversas, pero pocos críticos negarán que sus obras revolucionaron el ambiente teatral. La influencia ibseniana sobre Shaw se hizo sentir no sólo en el fondo, sino que además en su técnica dramática. Las obras más importantes del noruego son de ambiente doméstico y con el fin de captar aún mejor aquel ambiente, impartió a su diálogo una mayor naturalidad al desechar los recursos favoritos del teatro romántico: el soliloquio y el aparte. El autor que disponga de ellos para dar a 
conocer el pensamiento de sus personajes, descuidará la revelación psicológica a través del diálogo escénico. Ibsen logró, gracias a su innovación, una mayor espontaneidad de carácter, observando desde luego la norma de que el diálogo escénico debe ser más agudo y revelador, más incisivo y sugerente que la conversación cotidiana. El diálogo asumió total importancia en la revelación de carácter; incluso la acción pasó del terreno físico al psicológico. Ibsen, mediante el diálogo de sus personajes, mantiene vivo nuestro interés en un drama carente casi de acción física. La trama se desarrolla en el pensamiento. Nada verdaderamente sucede en Espectros; la psicología reina en Casa de Muñecas y en El pato salvaje. Asimismo, en Bernard Shaw son las ideas las que proporcionan el elemento de acción. El interés de Saint Joan, por ejemplo, no reside en el éxito inicial y posterior fracaso de la doncella como jefe militar ni en la guerra anglo-francesa, ni en su condenación como bruja al negar la autoridad de la iglesia doctrinaria. La obra, más bien, presenta la posición de un genio y santo que sufre la última pena porque su posición ideológica es contraria a las fuerzas del feudalismo y de la iglesia autoritaria, representadas por Warwick, Lemaitre y Cauchon. Shaw se esforzó en demostrar que ellos actuaron con sinceridad y de acuerdo con sus convicciones. No puede considerárseles villanos desde ningún punto de vista y aunque nuestras simpatías están siempre de parte de Juana, maravillosa creación de Shaw, el dramaturgo presenta ambos aspectos del problema -con justicia. Juana representa ideas contrarias a las establecidas en la sociedad de su tiempo y Shaw trata de justificar el proceder de sus jueces.

Es evidente que para poder apreciar este tipo de pieza teatral se precisa pensar. A manos de un dramaturgo medio, el tema hubiera tratado del éxito inicial y posterior fracaso de Juana como jefe militar, culminando con su ejecución en la plaza de Rouen. No pretendemos con esto decir que Ibsen y Shaw hayan sido los creadores del drama de ideas; Shakespeare, en Hamlet, escribió una obra de corte moderno, pues Hamlet es un drama introspectivo en que el conflicto se desarrolla en la mente del atormentado príncipe. Pero ese conflicto nos llega 
en gran parte por medio del soliloquio y además, se exterioriza en acción. Basta con comparar el número e importancia de los acontecimientos en Hamlet con una obra de Shaw para ver de qué manera el equilibrio entre palabras y acción se ha volcado en favor de las palabras. Shaw fué un maestro de la prosa límpida y pura que vierte su contenido en un continuo e inagotable hilo. Su penetrante inteligencia cuenta, para su expresión, con el dominio total de la lengua inglesa. Será imposible encontrar en la vasta obra literaria de Shaw, una idea confusa, ambigua o mal expresada. Sus diálogos y sus prefacios atraen como literatura para ser leída tranquilamente en casa, porque todo es clarísimo, porque no hay idea o concepto que no sea inmediatamente captable. Shaw dijo en cierta ocasión: "La totalidad del vocabulario inglés, desde Shakespeare hasta la última edición de la Enciclopedia Británica, me pertenece de tal manera que jamás me he visto en la necesidad de recurrir a un tesauro, excepto una o dos veces para cncontrar un tercer o cuarto sinónimo". Hesketh Pearson cuenta que a los cinco o seis años Shaw no leía las acostumbradas lecturas infantiles por encontrarlas "aburridas e insinceras"; pero sí léáa Pilgrim's Progress de Bunyan, Las mil y una noches, $y$ entabló poco después dura lucha con Great Expectations y $A$ Tale of Two Cities, libro del cual obtuvo sus primeros conocimientos de la revolución francesa.

"Cuando hube alcanzado la edad cínica y blasé de los doce o trece años había leído Pickwick Papers, Bleak House y las obras intermedias... antes de los diez años ya estaba saturado de Shakespeare y de la Biblia". Shaw demuestra en sus páginas una extraordinaria maestría del idioma, maestría que unida a una facilidad de expresión poco común, que jamás se convierte en hueca palabrería. En realidad nuestro dramaturgo rehuye todo preciosismo; la efectividad de su diálogo depende de un lenguaje sencillo pero incisivo. La práctica adquirida en su juventud cuando tan a menudo hizo uso de la palabra en mítines callejeros, le proporcionó su característica facilidad para encontrar le mot juste. Shaw posee un dominio absoluto de la retórica, pero la subordina en todo momento a sus necesidades para que la belleza intrínseca de los vocablos no ạdormezca a su auditorio. Estos pasajes 
majestuosos son, en consecuencia, cortos y contados; pero figuran entre los más selectos e inspirados escritos en lengua inglesa. Citaremos como ejemplos la alocución de César ante la esfinge en Caesar and Cleopatra, la escena en que Juana de Arco prefiere la muerte al presidio perpetuo que le niega el sol y la vida, el último parlamento de Lilith en Back to Methusela y la escena inicial de The Apple Cart. Estos personajes colocan a Shaw entre los grandes cultores y estilistas de la prosa inglesa.

Shaw posee otro talento que le ayudó a ser escuchado: un agudo sentido del humor, arma sin la cual sus numerosas obras hubieran perdido gran parte de su efectividad. La chispeante vena humorística del dramaturgo aparece en todo momento, sea ya en sus diálogos, o en forma de paradoja o fino epigrama. Shaw, a la manera de otros escritores irlandeses, ataca a la pomposa dignidad por medio de su ingenio y a menudo es él mismo la víctima del ataque. Pensamos aquí en las referencias que hace a sí mismo en algunas comedias, The Doctor's Dilema, How he lied to her Husband y Fanny's First Play, entre otras. Aunque han transcurrido sesenta años desde su debut como dramaturgo y muchos problemas que él presentó en sus obras han dejado ya de serlo, puede leerse a Shaw con igual gusto gracias a su alegría y humor insuperables. La tesis pasa, pero queda su manera de plantearla y de hacerla aceptable. La inteligencia de Shaw junto con su clara exposición unidas a su inagotable ingenio le aseguran un público durante mucho tiempo. Shaw es tan serio como Ibsen en su actitud frente a la vida y sus problemas; pero en virtud de su humor es más sano de espíritu que Ibsen, quien fué incapaz de reír. Shaw es una especie de filósofo riente que mantiene despierto el interés del público en una tesis mediante el elemento de humor. En el teatro de Shaw no nos interesa tanto saber lo que los personajes harán, como lo que van a decir y la forma en que lo expresarán. El mismo Shaw expone su punto de vista en el prefacio a la edición de sus obras completas (Odhams Press Limited, London), y lo hace con el buen humor, la lucidez y, digámoslo también, la jactancia que le son característicos. 
"Now it may be that a pen portrait of an imaginary monster with my name attached to it may already have taken possession of your own mind through your inevitable daily contact with newspaper press. If so, please class it with the unicorn and the dragon, the jabberwock and the bandersnatch, as a creature perhaps amusing but certainly entirely Fabulous. If you are to get any good out of me you must accept me as a quite straightforward practitioner of the art I make my living by. Inasmuch as that living depends finally on you as reader or playgoer or both. I am your very faithful servant; and I should no more dream of pulling your leg or trifling with you or insulting you than any decent skopkeeper would dream of doing that to his best customers. If I make you laugh at yourself, remember that my business as a clasic writer of comedies in "to chasten morals with ridicule"; and if I sometimes make you feel like a fool, remember that I have by the same action cured your folly, just as the dentist cures your toothache by pulling out your tooth. And I never do it without giving you plenty of laughing gas" (1).

"To chasten morals with ridicule" es una frase que le calza perfectamente. Y, a decir de Shaw, había mucho que reformar en su país. Leamos estas palabras suyas escritas al Comité Parlamentario de Censura Teatral:

"I am not an ordinary playwright in general practice. I am a

(1) "Ahora bien, puede ser que ya exista en vuestras mentes un retrato imaginario vinculado a mi persona, obtenido a través de vuestro inevitable contacto con la prensa. Si esto es así, colocadlo junto a la fauna legendaria: junto al unicornio, al dragón, al jabberwock y al bandersnatch (invenciones de Lewis Carroll) como un ejemplo divertido pero por cierto enteramente imaginario. Si algún provecho queréis sacar de mí, debéis aceptarme como un artífice honrado de la profesión que me da el sustento. En cuanto a la fuente de mis entradas depende de vosotros en vuestra calidad de público lector y de adictos al teatro, me declaro vuestro humilde servidor. Y ni yo con respecto a mi público así como tampoco un comerciante honrado con respecto a su clientela, osaríamos mofarnos de cllos - tomarlos con ligereza o insultarlos. Si os hago reír de vosotros mismos, recordad que mi función de comediógrafo clásico consiste en purificar la moral por medio del ridículo, y si a veces ello va en desmedro de vuestra persona, recordad que a la vez os he curado de vuestros desatinos por un procedimiento similar al del dentista que se ve obligado a extraer el diente para curar el dolor. $Y$ nunca lo hago sin daros una buena dosis de gas hilarante". 
specialist in immoral and heretical plays... in particular, I regard current morality as to economic and sexual relations as disastrously wrong; and I regard certain doctrines of the Christian religion as understood in England today with abhorrence. I write plays with the deliberate intention of converting the nation to my opinions in this matters. I have no other object in writing plays" (2). Son ellas palabras fuertes que expresan su actitud racionalista y que ilustran su constante cruzada contra los falsos valores que enturbian la actitud del individuo ante la sociedad. Las obras de Shaw abundan en personajes honrados y bien intencionados pero que, por falta de un espíritu analítico, ignoran la "verdadera realidad" existente detrás de la costumbre. Así en Widowers Houses, Shaw nos presenta a Harry Trench, simpático y correcto joven vinculado a la aristocracia londinense, pero que jamás ha pensado de dónde proviene la renta que percibe. Al descubrir el origen de ella (los barrios pobres) que resultan ser también la fuente de riqueza de su prometida, se suscita un problema de conciencia en la mente de Harry. Mrs. Warren's Profession expone el caso de una señora que con el fin de evitarle a su hija los padecimientos de la pobreza, con gran sensatez se convierte en propietaria de casas de prostitución. Su hija, que ha recibido una educación esmerada con esos dineros, termina por repudiarla. The Doctor's Dilema tiene como tesis básica la alternativa en la decisión que deberá tomar Sir Colenso Didgeon: o salvar la vida de un genio desprovisto enteramente de moralidad y decencia humanas, o la de un hombre pobre, pero de honradez y virtudes incontestables. En Major Barbara, Shaw presenta la procedencia de los fondos que mantienen a ciertas instituciones religiosas, fondos obtenidos de las utilidades de la venta de alcohol y de las fábricas de armamentos de Andrew Undershaft.

Se le objeta a Shaw que sus personajes carecen de emoción huma-

(2) "Yo soy un dramaturgo corriente en ejercicio de su profesión. Soy un especialista en obras inmorales $y$ herejes... considero que la moral reinante en lo económico y en lo sexual es completamente errónea. Y miro con aversión ciertas doctrinas cristianas como se las entiende hoy en Inglaterra. Escribo mis obras con la intención deliberada de lograr que la nación adopte mis opiniones ẹn estas materias. Es ésta la única finalidad que persigo en mis obras", 
na, y que son incapaces de existir fuera del marco que Shaw les impone en sus obras. Son figuras intelectuales que actúan en calidad de portavoces para emitir las numerosas opiniones de su creador. Puede que la acusación se justifique; pero debe dejarse algo en claro antes de aceptar tal aseveración: lo viviente en Shaw son las ideas y el papel principal de sus personajes está supeditado a la expresión de ellas con toda premeditación. Shaw jamás intentó crear personajes de carne y hueso con las complejidades que forman parte integral de los seres vivientes. Shaw, como persona, siempre amó lo bueno y lo sencillo, y quiso imponer la bondad y la comprensión ante la sociedad humana. Atacó la hipocresía y no titubeó en denunciar valientemente todo lo que estimó falso y nocivo en las costumbres de su tiempo. Shaw amó y comprendió el sacrificio desinteresado. De ahí el encanto de personajes como Juana, Dick, Dudgeon en The Devil's Disciple y la inmortal Cándida. Vistos en conjunto, ellos representan algo más que una colección de figuras de cera; brindan una visión gigantesca del panorama social, cuyas debilidades Shaw quiso atacar para mayor gloria del mundo y del individuo. La panacea de Shaw consiste en la inteligencia. Un orden inteligente en lo social, lo económico y lo espiritual traería consigo una solución a la infelicidad imperante.

A través de sus obras Shaw iluminó el camino para lograr una mayor felicidad sobre la base del autoanálisis social. Ya despejada la mente de falsos conceptos y falacias que rigen el medio ambiente se puede encarar sensatamente la realidad. Sin embargo, Shaw no fue aquella máquina racionalista, todo intelecto y eficiencia analítica, que él mismo se esforzó en propagar como el reflejo de su verdadera personalidad. Detrás de esa cortina hubo un hombre generoso y noble, una persona amable y modesta que se manifestaba en su vida privada. A pesar de su posición antirromántica, este hombre amó la música de Ricardo Wagner y de vez en cuando resalta en su obra la poesía, personificada en Juana de Arco, Cándida y Jennifer Dubedat (The Doctor's Dilema), para nombrar sólo a tres de sus imperecederas heroínas. Se sabe que ayudó económicamente a muchos seres necesitados y su eterna batalla contra la pobreza como uno de los peores males que 
azotan a la humanidad, le indujo a hacer estudios profundos de las ciencias económicas. Fué un enemigo declarado de la crueldad y de la injusticia, un hombre lleno de compasión por sus semejantes. Su socialismo es el fruto de su creencia en la igualdad fundamental de todos los seres vivientes.

Se le han hecho críticas ásperas y personales; pero cuenta también con defensores que han sabido medir el valor de su obra. El difunto dramaturgo James Bridie escribió poco antes de su muerte en 1951: " $\mathrm{He}$ is one of the three or four men in the four hundred years of the existence of the English theatre who have attracted attention all through the civilized world", para continuar más adelante: "He loved the theatre. It was his church. But he looked on his church as a part of life and not as a thing apart. His plays, with all due respect to his critics, borrows their vivid colours from life" (3).

Sus obras vivirán por su estilo, por el afilado intelecto y genial espíritu polemista de su autor y por la completa sinceridad con que él abordó los problemas sociales de su tiempo.

(3) "Es uno de los tres o cuatro hombres en los cuatro siglos de la existencia del teatro inglés que ha atraído la atención del mundo civilizado... Amó el teatro. Era su templo. Pero lo consideró siempre como parte de la vida y no como algo ajeno a ella. Sus obras, con el debido respeto a sus críticos, extrajeron sus vivos colores de la vida misma". 